$8^{\text {th }}$ International Conference on Management, Economics and

Humanities

7 - 9 December, 2018

Barcelona, Spain

\title{
MEASURING THE EFFICIENCY OF ONLINE ORDERING AND DELIVERY FACILITY FOR FOOD
}

\author{
Dr. Uma Shankar Singh \\ Faculty of Administrative Sciences and Economics
}

ISHIK University, Erbil-Kurdistan

\begin{abstract}
The exploratory research conducted here to understand the potential lying with third party service provider for online ordering and physically food distribution system. The study is conducted in Irbil city of Kurdistan, which was in a slow move of economy since attack of ISIS to Iraq. Now the city has come on revival and getting the momentum again in all business. Kurdish culture is rich in having food with both fast food and restaurants. A new business entity has emerged as a service provider for online order booking and delivering food products from production point to delivery point for customers as per booked order and address. The efficiency of the company is the most crucial for the sustainability of the business. The study is focused on: to explore characteristics of food supply chain organizations, to assess the efficiency of online ordering and delivery facility, to predict the suitability of business model. The research methodology adopted has the descriptive study with the collection of secondary data for concept clarity and primary data for the efficiency assessment of existing business model. A cross sectional study conducted using a well-structured survey questionnaire on the sample size 126 selected using the simple random sampling method of probability sampling. Data analyzed statistically with Independent Sample T-test, Paired sample T-test, ANOVA and regression using SPSS. The outcome of the research is an analytical support for the food distribution companies, fast food stores and restaurants.
\end{abstract}

Keywords: assessment; delivery; distribution; food; restaurants; service; supply. 
